\title{
Pre-Retinal Arteriolar Loop
}

National Cancer Institute

\section{Source}

National Cancer Institute. Pre-Retinal Arteriolar Loop. NCI Thesaurus. Code C161569.

Arteriole emerging from the central retinal artery, coursing through the posterior

vitreous and reconnecting to the inner retina. (INHAND) 